Article

\title{
The Effects of Wild Ginseng Extract on Psychomotor and Neuromuscular Performance Recovery Following Acute Eccentric Exercise: A Preliminary Study
}

\author{
Hyun Chul Jung ${ }^{1}\left(\mathbb{D}\right.$, Nan Hee Lee ${ }^{2}$, Young Chan Kim ${ }^{3}$ and Sukho Lee ${ }^{2, *(\mathbb{D}}$ \\ 1 Department of Coaching, College of Physical Education, Kyung Hee University-Global Campus, \\ 1732 Deokyoungdaero, Giheung-gu, Yongin-si, Gyeonggi-do 17014, Korea; jhc@khu.ac.kr \\ 2 Department of Counseling, Health, and Kinesiology, College of Education and Human Development, \\ Texas A\&M University-San Antonio One University Way, San Antonio, TX 78224, USA; \\ nanhee.lee@biosci.gatech.edu \\ 3 Korea Food Research Institute, 245, Nongsaengmyeong-ro, Iseo-myeon, Wanju-gun, \\ Jeollabuk-do 55365, Korea; yckim@kfri.re.kr \\ * Correspondence: slee@tamusa.edu; Tel.: +(1)210-784-2537
}

Received: 30 July 2020; Accepted: 21 August 2020; Published: 23 August 2020

\begin{abstract}
To examine the efficacy of wild ginseng extract (WGE) on psychomotor and neuromuscular performance recovery following acute eccentric exercise. This study was a double-blind, crossover, and placebo-controlled design with a 14-day washout period. Ten male adults, aged $27.1 \pm 4.33$ years old, voluntarily participated in the study. Subjects were assigned to one of two parallel conditions (WGE or placebo) in a counterbalanced manner. Subjects consumed two packs of WGE ( $350 \mathrm{mg} /$ package) or placebo drink immediately after acute eccentric exercise and the following four days. The eccentric exercise consisted of $20 \mathrm{~min}$ of downhill running at $60 \% \mathrm{fo}_{2 \text { peak }}$ and five sets (of 20) of drop jump exercise. Computer-based cognitive function test and neuromuscular performance tests, including straight leg raise, vertical jump, isometric leg strength, and anaerobic power test were administered four times, at baseline, $2 \mathrm{~h}, 48 \mathrm{~h}$, and $96 \mathrm{~h}$ after acute exercise. The interleukin-6 (IL-6), myoglobin, cortisol, total antioxidant capacity (TAC), and perceived muscle soreness were also assessed at each time point. A significance level was set at 0.05 . No significant differences between the WGE and the placebo groups were observed in psychomotor and neuromuscular performance variables. Blood markers, including IL-6 ( $\mathrm{p}=0.013)$, myoglobin $(\mathrm{p}<0.001)$, and cortisol level $(p=0.047)$ were changed significantly across the time. A post-hoc test revealed that a significant increase in IL-6 was observed only in the placebo group $(p=0.014)$, while no significant changes found in the WGE condition. The perceived muscle soreness was not different between the WGE and the placebo conditions. The administration of WGE immediately after acute eccentric exercise and the following four days have no benefits on psychomotor and neuromuscular performance recovery in healthy adults. However, the acute WGE supplementation may attenuate the eccentric exercise-induced inflammatory process, such as IL-6, but future study with a large sample size is required to clarify the anti-inflammation process in response to acute eccentric exercise.
\end{abstract}

Keywords: ginseng; performance; recovery; eccentric exercise; inflammation

\section{Introduction}

Ginseng is a popular selling product among herbal medicines and it has a long history concerning its efficacy on adaptogenic properties, such as stress management and fatigue recovery among Asian countries [1,2]. Various ginsengs, such as Cultivated Ginseng, Mountain Cultivated Ginseng, and Wild Ginseng have been introduced based on the grown environment and harvest methods [3]. Wild 
ginseng is grown in nature for an extended period to propagate in the mountain, while other ginsengs cultivate within 5-6 years in a farmland or mountain [3]. Chemical components of ginseng are also varied, depending on cultivation methods and curing processes [4]. One of the active ingredients, known as ginsenosides, plays an essential role in anti-inflammatory agents [5], and supplementation of these ingredients has been used to address the risk factors of cardiovascular diseases (CVDs) [6]. Over 40 different kinds of ginsenosides, such as Rb1, Rb2, Rc, Rd, Re, Rf, Rg1, Rg2, Rg3, Rh1, Rh2 have been identified to date, and the ginsenosides are determined by their positions on thin-layer chromatograms [5]. It has been reported that ginseng extract improves brain function, neuromuscular strength, and endurance [7-10]. Additionally, a decrease in anxiety and depression [11], as well as an increase in cognitive function [12] have been observed following ginseng supplementation. For these reasons, ginseng has been administrated not only for natural herb medicines but also for health supplements $[13,14]$. Recently, it is believed that ginseng may act as an ergogenic aid or recovery facilitator [15]. However, the ergogenic effects on physical performance is still unclear due to inconsistent results from the previous studies [2,16].

Participating in regular exercise and physical activity improves physical performance and immune function $[17,18]$. However, acute strenuous exercise or intense eccentric exercise can cause the disturbance of intracellular pro-oxidant-antioxidant homeostasis that leads to an increase in the accumulation of inflammation [19]. For instance, Banerjee et al. reported that an acute bout of exercise and/or prolonged intense exercise may cause a transient reduction and damage of various body tissues due to the augment exercise-induced oxidative stress [20]. In other words, performing one-off intense exercise can cause physiological imbalances, and this imbalanced physiological function is linked to immune dysfunction, lipid peroxidation, and free radical production. One of the common symptoms following intense or eccentric exercise is muscle soreness. Particularly, repetitive eccentric contraction exercise causes severe muscular pain 2-3 days later, which is known as Delayed Onset Muscle Soreness (DOMS) [21]. This acute muscle soreness is initially identified at the muscle/tendon junction, and then is gradually widespread to the entire muscle group [21]. An increase in muscle damage and soreness following intense or eccentric exercise affects performance recovery [22] as well as cognitive function [23].

Nutritional supplementation, such as ginseng, may be one feasible nutritional option to attenuate exercise-induced inflammation, as well as to facilitate performance recovery. Previous studies have reported that ginseng supplementation improves endurance performance [24-26], but fewer studies have been examined in other performance areas, such as neuromuscular performance. Pumpa et al. reported that ginseng supplementation following downhill running exercise was not associated with jump performance recovery in well-trained males [27]. Recently, a meta-analysis study demonstrated that there was a significant effect on fatigue recovery following ginseng supplementation, but the author pointed out that insufficient literature may not guarantee its efficacy on fatigue recovery [2]. We believe that well-designed studies are necessary to clarify the efficacy of ginseng supplementation on performance recovery, especially neuromuscular performance in healthy adults. Therefore, the purpose of this study was to examine the effects of wild ginseng extract on psychomotor and neuromuscular performance recovery following acute eccentric exercise.

\section{Materials and Methods}

\subsection{Subjects}

Subjects were randomly recruited by flyer and oral presentation in the university. Inclusion criteria of subjects were a) male adults aged from 18 to 40 years old, b) have no health problems, including skeletomuscular injuries, cardiovascular or pulmonary diseases, and c) have no experience using any ginseng supplementations. Subjects who were a) not able to participate in the physical activity or b) take any herbal-related medications were excluded from the study. Initially, 12 subjects agreed to participate the study, but only 10 subjects completed all procedures. Two participants voluntarily 
dropped out of the study for personal reasons (i.e., lack of interest, personal reason). All subjects received oral explanations, including the study procedure, possible risk, and benefits. Participants completed a physical activity readiness questionnaire (PAR-Q) and a written risk stratification screening form. When participants reported no issues with exercise, resting heart rate and blood pressure were taken, according to the American College of Sports Medicine (ACSM) guidelines. A written consent form approved by the Institutional Review Board of Texas A\&M University, San Antonio, (\#2015-126), was obtained from each subject.

\subsection{Experimental Design}

This study was a double-blind, randomized crossover design. All subjects participated in the pre-tests baseline measurements for their basic characteristics, including body weight, height, resting blood pressure, body composition, and peak oxygen uptake $\left(\mathrm{VO}_{2}\right.$ peak). Then, subjects visited the laboratory three times (1st, $3 \mathrm{rd}, 5$ th day) to complete the first supplementation trial. Subjects performed the acute eccentric exercise, including $20 \mathrm{~min}$ of downhill running and five sets of 20 drop-jump exercises. The wild ginseng extract (WGE) or placebo drink was given to subjects immediately after the acute eccentric exercise and the following 4-day period. The WGE and placebo drink were in the identical packs manufactured by the Korea Food Research Institute. The dependent variables, including computer-based cognitive function test, physical performance test, blood analysis, and perceived muscle soreness were measured four times, at baseline, $2 \mathrm{~h}, 48 \mathrm{~h}$, and $96 \mathrm{~h}$ after the acute eccentric exercise. The second trial was conducted after a 14 days washout period. The procedure for the second trial was the same as the first trial, with different supplement. All tests were performed at the Human Performance Laboratory in the university. The time points of each measurement are presented in Table 1.

Table 1. The time points of measurements.

\begin{tabular}{|c|c|c|c|c|c|c|c|}
\hline Variables & Base & $\begin{array}{l}\text { Eccentric } \\
\text { Exercise }\end{array}$ & $2 \mathrm{~h}$ & $24 \mathrm{~h}$ & $48 \mathrm{~h}$ & $72 \mathrm{~h}$ & $96 \mathrm{~h}$ \\
\hline $\begin{array}{ll}\text { - } & \text { Psychomotor Performance } \\
\text { - } & \text { Neuromuscular Performance } \\
\text { - } & \text { Blood Analyses } \\
\text { - } & \text { Perceived Muscle Soreness }\end{array}$ & $\checkmark$ & $\begin{array}{l}\text { Downhill Running } \\
\text { and } \\
\text { Drop Jump Exercise }\end{array}$ & $\checkmark$ & & $\checkmark$ & & $\checkmark$ \\
\hline
\end{tabular}

\subsection{Supplementation}

The WGE used in this study was $350 \mathrm{mg}$ of cultivated wild ginseng extract in $140 \mathrm{~mL}$ packages. Subjects took two packs of WGE (WGE powder $350 \mathrm{mg} /$ package) a day for five days after acute eccentric exercise. The ingredients of WGE drinks were composed of $13.8 \%$ of Korea wild ginseng, $1.5 \%$ of soy powder, $1.5 \%$ of almond paste, $1.75 \%$ of isomaltooligosaccharide, $1.75 \%$ of fructooligosaccharide, $0.05 \%$ of refined salt, $0.05 \%$ of scented almond, $0.025 \%$ of xanthan gum, $0.19 \%$ of sodium bicarbonate, $0.05 \%$ of grapefruit seed extract, and $79.335 \%$ of water. The placebo drink was manufactured to be identical in appearance and content, except the ginseng extract. The placebo contained $0.25 \%$ of scented ginseng, $1.5 \%$ of soy powder, $1.5 \%$ of almond paste, $1.75 \%$ of isomaltooligosaccharide, $1.75 \%$ of fructooligosaccharide, $0.05 \%$ of refined salt, $0.05 \%$ of scented almond, $0.025 \%$ of xanthan gum, $0.19 \%$ of sodium bicarbonate, $0.05 \%$ of grapefruit seed extract, and $92.885 \%$ of water. The WGE and placebo drink were provided by Korea Food Research Institute. Supplements were given to subjects in a counterbalanced manner to minimize the order effect. Subjects were asked not to consume any caffeine-containing (i.e., coffee, energy drink) or herbal-containing beverages during the intervention.

\subsection{Pre-tests}

The pre-tests included body weight, height, resting blood pressure, body composition, and VO2peak test. Subjects' body height and weight were measured by a wall stadiometer (PAT \#290237, 
Novel Products, Rockton, USA) and a digital weight scale (HD-366, Tanita, Tokyo, Japan). Then, resting blood pressure was measured using an autonomic device (BP79IT, Omron, Japan). Systolic blood pressure, diastolic blood pressure, and resting heart rate were recorded. Three sites of skinfold thickness, including chest, abdominal, and thigh were measured with a skinfold caliper (PAT \#3008239, Beta Technology, Santa Cruz, USA) to estimate body composition. Each site was measured three times by the trained technician and an average value was recorded. The body density and body fat percentage was estimated by Jackson and Pollock and Siri's equation, respectively $[28,29]$. The $\mathrm{VO}_{2}$ peak test was performed to accurately prescribe the exercise intensity for downhill running. The subject sat on the chair and wore a mask that connected with a metabolic cart (TrueOne 2400, Medics, USA). When the subject's respiratory exchange ratio (RER) dropped below 0.75 , the graded exercise test begun on the treadmill. The Bruce protocol was applied at a speed of $2.74 \mathrm{~km} / \mathrm{h}$ and a $10 \%$ grade. The speed and grade gradually increased every 3 min until subjects reached exhaustion. The $\mathrm{VO}_{2}$ peak test was terminated when subjects met at least two of the following conditions: (a) showed signs of intense effort (heavy breathing, facial flushing, unsteady gait, and sweating), (b) respiratory exchange ratio (RER), 1.15, (c) rating of perceived exertion (RPE) $\geq 19$ (Borg 6-20 scale), or (d) volitional fatigue.

\subsection{Acute Eccentric Exercise}

The acute eccentric exercise program consisted of downhill running and drop jump exercise. The exercise program was modified based on the previous studies [30,31]. Prior to exercise, subjects performed jogging for $5 \mathrm{~min}$ on the 0 -graded treadmill. Then, subjects performed downhill running for $20 \mathrm{~min}$ on a treadmill with a grade lowered to $-10^{\circ}$. The speed of downhill running was set at $60 \%$ of the subject's $\mathrm{VO}_{2}$ peak. The average speed of downhill running was $6.4 \pm 1.11 \mathrm{~km} /$ hour. After the downhill running, subjects performed drop jump exercises-five sets of 20 maximal drop jumps from the height of a $60 \mathrm{~cm}$ box. There was a 2-min rest interval between sets.

\subsection{Psychomotor and Physical Performance Tests}

Psychomotor performance test: to assess the subject's psychomotor performance, the computer-based cognitive function test was performed. Prior to the test, subjects performed one trial for the familiarization during the pre-test. The test included psychomotor vigilance task (PVT) and delayed-match-to-sample task (DMS). The PVT test was composed of 40 trials for 5 min to assess mean reaction time while the DMS test consisted of 20 trials $20 \mathrm{~min}$ to assess memory ability [32].

Physical performance test: the physical performance test included straight leg raise, vertical jump performance, isometric leg strength, and anaerobic power. The straight leg raise was measured with a goniometer (Baseline stainless steel goniometers, USA) to evaluate the range of motion. The subjects lay on the medical bed in a supine position. Then, the subject raised the dominant leg as high as possible with the knee fully extended while the opposite leg remained on the bed firmly without movement [33]. Each subject performed two trials and the best score was recorded. Vertical jump performance was measured to evaluate the explosive power. The subject raised the dominant arm, fully extended, on the measuring board, and the point was marked as an initial point. Then, subjects performed a countermovement jump as high as possible and marked the highest point. The vertical jump performance (VJP )was calculated from the maximal jump height minus the initial point. Each subject performed three times with one-minute interval between trials, and the best score was recorded [33]. Isometric leg strength was measured by a hand-held dynamometer (Lafayette Instruments, Lafayette, USA). The device was validated in previous studies [34-36] and has been used to measure isometric muscle strength in healthy subjects [37]. Subjects were seated on the table in a supine position, and the knee and hip were positioned 90 degrees. The handheld dynamometer force pad was placed just proximal to the ankle joint area and the subject's knee extensor and flexor strength was recorded in kilogram force. All subjects performed two maximal isometric leg extension and flexions, holding for 3 to $5 \mathrm{~s}$ with a minute rest interval between trials. The highest score was recorded. Lastly, subjects performed anaerobic power tests measured by an Automatic Power Cycle 
(Power Cycle, Austin, TX, USA). The device has been validated in previous studies [36]. First, subjects performed 2 min of warm-up cycling at 100 to $120 \mathrm{rpm}$ with power of 100 to 120 Watt. Then, subjects performed cycling maximally for approximately $5 \mathrm{~s}$. Each subject performed four trials with one-minute intervals between trials, and the highest peak and mean power were recorded [37]. Standardized verbal encouragement was applied to all subjects for their maximal performance.

\subsection{Blood Analyses}

Blood sample was collected four times at baseline, $2 \mathrm{~h}, 48 \mathrm{~h}$, and $96 \mathrm{~h}$ after acute exercise to analyze the markers of inflammation (interleukin 6; IL-6) and muscle damage (cortisol, myoglobin) as well as antioxidant capacity (total antioxidant capacity). Moreover, $3 \mathrm{~mL}$ of blood sample was withdrawn from an antecubital vein at each time point by the trained phlebotomist. The collected blood samples were drawn into a tube containing ethylenediaminetetraacetic acid (EDTA) to prevent coagulation. Then, the blood samples were centrifuged at $3000 \mathrm{rpm}$ for $10 \mathrm{~min}$. The upper layer of plasma was transferred into a conical tube and stored at $-80^{\circ} \mathrm{C}$. Inflammation and muscle damage markers, including IL-6, myoglobin, and cortisol were analyzed by the enzyme-linked immunosorbent assay (ELISA) method using a commercially available Human ELISA IL-6 kit (EMD Millipore, Germany), myoglobin kit (EIA, Biocheck, USA), and cortisol kit (ELISA, DRG, USA). Total antioxidant capacity (TAC) was analyzed with the ELISA method using an antioxidant assay kit (total antioxidant, USA). All measurements were performed in duplicate. The coefficient variation (CV) of all blood analyses were below $10 \%$.

\subsection{Perceived Muscle Soreness}

Perceived muscle soreness was measured by a Visual Analogue Scale (VAS). The scale was distributed from 0 to 10 scales where ' 0 ' indicated not sore at all, and ' 10 ' indicated maximal soreness. Subjects were asked to point the score four times, at baseline, $2 \mathrm{~h}, 48 \mathrm{~h}$, and $96 \mathrm{~h}$ after the acute eccentric exercise.

\subsection{Data Analysis}

All data analyses were performed by a computer software program (SPSS version 25.0, SPSS Inc., Chicago, IL, USA). Prior to the data analyses, a Kolmogorov-Smirnov test was applied to check the normality of data. All variables exhibited normal distribution. Descriptive statistics, including mean, standard deviation (SD), and 95\% confidence interval were computed for all variables. The repeated analysis of variances (ANOVAs) for conditions (WGE vs. placebo) by time (baseline, $2 \mathrm{~h}, 48 \mathrm{~h}$, $96 \mathrm{~h}$ after acute exercise) were applied to assess the effects of WGE on dependent variables. If any significant interaction or main effects were identified, paired test for condition effects and repeated ANOVA with least significant difference (LSD) post-hoc test for time effects were applied. The effect size was presented as a partial eta-squared $\left(\eta_{\mathrm{p}}{ }^{2}\right)$ value. The effect size can be considered as "large effect", if the value is 0.14 or higher [38]. The level of statistical significance was set at 0.05 .

\section{Results}

\subsection{Basic Characteristics}

All participants underwent pre-examination, including height, weight, resting blood pressure, heart rate, body fat percentage, and $\mathrm{VO}_{2}$ peak tests. The results are presented in Table 2 .

\subsection{Psychomotor and Neuromuscular Performance}

The results of psychomotor performance are shown in Table 3. No significant interaction effects for condition by time were observed in the psychomotor performance, including psychomotor vigilance task (PVT) and delayed-match-to-sample task (DMS). However, the DMS correction ( $\mathrm{F}=8.844, \mathrm{p}=0.019$, $\left.\eta_{\mathrm{p}}{ }^{2}=0.317\right)$ and DMS time $\left(\mathrm{F}=4.961, \mathrm{p}=0.025, \eta_{\mathrm{p}}{ }^{2}=0.355\right)$ were significantly reduced across the time in both conditions. Regarding neuromuscular performance, no significant interaction effects for 
group by time were also identified in all performance variables. However, there was a significant time effect on straight leg raise $\left(F=4.100, p=0.030, \eta_{p}^{2}=0.313\right)$ where the straight leg raise value was significantly greater at $96 \mathrm{~h}$ compared to $2 \mathrm{~h}$ after exercise. The results of physical performance are presented in Table 4.

Table 2. Participants' basic characteristics.

\begin{tabular}{cc}
\hline Variables & Mean (SD) \\
\hline Age (year) & $27.1(4.33)$ \\
\hline Height $(\mathrm{cm})$ & $174.8(9.39)$ \\
\hline Weight $(\mathrm{kg})$ & $78.0(13.70)$ \\
\hline Resting Systolic Blood Pressure $(\mathrm{mmHg})$ & $117.8(17.84)$ \\
\hline Resting Diastolic Blood Pressure $(\mathrm{mmHg})$ & $73.4(9.42)$ \\
\hline Resting Heart Rate (beats $/ \mathrm{min})$ & $65.4(7.96)$ \\
\hline Body fat $(\%)$ & $12.7(4.43)$ \\
\hline $\mathrm{VO}_{2}$ peak $(\mathrm{ml} / \mathrm{kg} / \mathrm{min})$ & $44.9(7.48)$ \\
\hline
\end{tabular}

Table 3. The results of psychomotor performance following acute eccentric exercise.

\begin{tabular}{|c|c|c|c|c|c|c|c|c|}
\hline \multirow{2}{*}{ Variables } & \multirow{2}{*}{ Group } & \multirow{2}{*}{ Base } & \multirow{2}{*}{$2 \mathrm{~h}$} & \multirow{2}{*}{$48 \mathrm{~h}$} & \multirow{2}{*}{$96 \mathrm{~h}$} & \multicolumn{3}{|c|}{ p-Value } \\
\hline & & & & & & G & $\mathbf{T}$ & $\mathrm{G} \times \mathrm{T}$ \\
\hline \multirow{6}{*}{$\begin{array}{c}\text { PVT } \\
\text { Correctness } \\
\text { (score) }\end{array}$} & Placebo & 36.7 & 37.7 & 37.7 & 37.3 & \multirow{6}{*}{0.568} & \multirow{6}{*}{0.498} & \multirow{6}{*}{0.969} \\
\hline & (SD) & -3.91 & -2.16 & -2.21 & -5.17 & & & \\
\hline & $95 \%$ CI & $33.9-39.5$ & $36.2-39.2$ & $36.1-39.3$ & $33.6-41.0$ & & & \\
\hline & WGE & 37.2 & 37.9 & 38.1 & 37.5 & & & \\
\hline & (SD) & -3.77 & -3.21 & -2.77 & -4.17 & & & \\
\hline & $95 \%$ CI & $34.5-39.9$ & $35.6-40.2$ & $36.1-40.1$ & $34.5-40.5$ & & & \\
\hline \multirow{6}{*}{$\begin{array}{c}\text { PVT } \\
\text { reaction time } \\
(\mathrm{msec})\end{array}$} & Placebo & 335.3 & 338.8 & 340 & 346.1 & \multirow{6}{*}{0.073} & \multirow{6}{*}{0.355} & \multirow{6}{*}{0.626} \\
\hline & (SD) & -34.07 & -28.4 & -26.07 & -32 & & & \\
\hline & $95 \%$ CI & $311.0-359.7$ & $318.5-359.1$ & $321.4-358.7$ & $323.2-369.0$ & & & \\
\hline & WGE & 345.2 & 350.3 & 345.8 & 349.2 & & & \\
\hline & (SD) & -32.12 & -34.29 & -33.24 & -39.13 & & & \\
\hline & $95 \% \mathrm{CI}$ & $322.3-368.2$ & $325.7-374.8$ & $322.0-369.6$ & $321.2-377.2$ & & & \\
\hline \multirow{6}{*}{$\begin{array}{l}\text { DMS } \\
\text { correctness } \\
\text { (score) }\end{array}$} & Placebo & 26.5 & $25.2 *$ & 26.7 & 26.7 & \multirow{6}{*}{0.136} & \multirow{6}{*}{0.019} & \multirow{6}{*}{0.768} \\
\hline & (SD) & -2.68 & -3.68 & -3.68 & -3.56 & & & \\
\hline & $95 \% \mathrm{CI}$ & $24.6-28.4$ & $22.6-27.8$ & $24.1-29.3$ & $24.2-29.2$ & & & \\
\hline & WGE & 27.3 & $26.0 *$ & 27.2 & 26.6 & & & \\
\hline & (SD) & -3.27 & -4 & -3.19 & -4.67 & & & \\
\hline & $95 \% \mathrm{CI}$ & $25.0-29.6$ & $23.1-28.9$ & $24.9-29.5$ & $23.3-29.9$ & & & \\
\hline \multirow{6}{*}{$\begin{array}{l}\text { DMS } \\
\text { time } \\
(\mathrm{msec})\end{array}$} & Placebo & 2942.1 & $2533.5 *$ & $2598.9 *$ & $2283.9 *$ & \multirow{6}{*}{0.272} & \multirow{6}{*}{0.025} & \multirow{6}{*}{0.416} \\
\hline & (SD) & -1948.13 & -1747.26 & -1495.75 & -1524.06 & & & \\
\hline & $95 \% \mathrm{CI}$ & $1548.5-4335.7$ & $1283.5-3783.4$ & $1528.9-3668.9$ & $1193.7-3374.2$ & & & \\
\hline & WGE & 3335.8 & $2507.6^{*}$ & $2806.3 *$ & 2908.4 * & & & \\
\hline & (SD) & -1948.13 & -1390.8 & -1849.86 & -1535.01 & & & \\
\hline & $95 \%$ CI & $1846.8-4824.7$ & $1512.7-3502.5$ & $1483.0-4129.6$ & $1810.3-4006.5$ & & & \\
\hline \multirow{6}{*}{$\begin{array}{c}\text { DMS } \\
\text { reaction time } \\
(\mathrm{msec})\end{array}$} & Placebo & 1784.9 & 1740.9 & 1711.7 & 1533.2 & \multirow{6}{*}{0.139} & \multirow{6}{*}{0.061} & \multirow{6}{*}{0.412} \\
\hline & (SD) & -715.58 & -790.94 & -516.6 & -518.58 & & & \\
\hline & $95 \%$ CI & $1273.0-2296.8$ & $1175.1-2306.7$ & 1342.1-2081.2 & $1162.3-1904.2$ & & & \\
\hline & WGE & 1905.1 & 1693.3 & 1881.8 & 1823.8 & & & \\
\hline & (SD) & -351.92 & -366.75 & -759.4 & -629.23 & & & \\
\hline & $95 \%$ CI & $1653.3-2156.8$ & 1431.6-1954.9 & $1338.5-2425.0$ & $1373.7-2274.0$ & & & \\
\hline
\end{tabular}

\footnotetext{
Note. ${ }^{*} \mathrm{p}<0.05$, indicate a significant different compared to baseline. DMS, delayed-match-to-sample task; $\mathrm{G}$,
} group; $\mathrm{G} \times \mathrm{T}$, group $\times$ time; msec, millisecond; $\mathrm{PVT}$, psychomotor vigilance task; T, time; WGE, wild ginseng extract. 
Table 4. The results of physical performance following acute eccentric exercise.

\begin{tabular}{|c|c|c|c|c|c|c|c|c|}
\hline \multirow{2}{*}{ Variables } & \multirow{2}{*}{ Group } & \multirow{2}{*}{ Base } & \multirow{2}{*}{$2 \mathrm{~h}$} & \multirow{2}{*}{$48 \mathrm{~h}$} & \multirow{2}{*}{$96 \mathrm{~h}$} & \multicolumn{3}{|c|}{ p-Value } \\
\hline & & & & & & G & $T$ & $G \times T$ \\
\hline \multirow{6}{*}{$\begin{array}{l}\text { Straight leg } \\
\text { raise }\left({ }^{\circ}\right)\end{array}$} & Placebo & 71.2 & 69.2 & 69.1 & $75.4 *$ & \multirow{6}{*}{0.29} & \multirow{6}{*}{0.03} & \multirow{6}{*}{0.412} \\
\hline & (SD) & -7.13 & -8.82 & -11.49 & -7.23 & & & \\
\hline & $95 \%$ CI & $65.5-77.1$ & $61.7-75.9$ & $59.2-77.7$ & $69.6-81.3$ & & & \\
\hline & WGE & 67.5 & 66.7 & 69.8 & $72.6^{*}$ & & & \\
\hline & (SD) & 7.32 & -5.44 & -7.13 & -4.5 & & & \\
\hline & $95 \%$ CI & $62.3-72.7$ & $62.8-70.6$ & $64.7-74.9$ & $69.4-75.8$ & & & \\
\hline \multirow{6}{*}{$\begin{array}{l}\text { Vertical Jump } \\
\qquad(\mathrm{cm})\end{array}$} & Placebo & 53.5 & 50.4 & 51.5 & 51.1 & \multirow{6}{*}{0.205} & \multirow{6}{*}{0.324} & \multirow{6}{*}{0.307} \\
\hline & (SD) & -6.93 & -7.92 & -9.12 & -6.62 & & & \\
\hline & $95 \%$ CI & $47.4-57.9$ & $43.5-56.1$ & $43.5-57.7$ & $45.4-56.0$ & & & \\
\hline & WGE & 50.6 & 50.1 & 49.8 & 51.2 & & & \\
\hline & (SD) & -8.62 & -7.06 & -6.76 & -7.79 & & & \\
\hline & $95 \%$ CI & $44.4-56.7$ & $45.1-55.2$ & $44.9-54.6$ & $45.6-56.8$ & & & \\
\hline \multirow{6}{*}{$\begin{array}{l}\text { Isometric Leg } \\
\text { extension (kg) }\end{array}$} & Placebo & 44.1 & 40.9 & 43.2 & 43.3 & \multirow{6}{*}{0.818} & \multirow{6}{*}{0.259} & \multirow{6}{*}{0.832} \\
\hline & (SD) & -9.3 & -9.49 & -11.1 & -11.9 & & & \\
\hline & $95 \%$ CI & $37.5-50.8$ & $34.1-47.7$ & $35.2-51.1$ & $34.8-51.8$ & & & \\
\hline & WGE & 44.9 & 42.1 & 42.2 & 43.3 & & & \\
\hline & (SD) & -11.04 & -13.04 & -9.02 & -9.75 & & & \\
\hline & $95 \%$ CI & $37.0-52.8$ & $32.8-51.4$ & $35.7-48.7$ & $36.3-50.2$ & & & \\
\hline \multirow{6}{*}{$\begin{array}{l}\text { Isometric Leg } \\
\text { Flexion (kg) }\end{array}$} & Placebo & 35.5 & 34.8 & 36.8 & 36.2 & \multirow{6}{*}{0.671} & \multirow{6}{*}{0.173} & \multirow{6}{*}{0.911} \\
\hline & (SD) & -8.77 & -7.54 & -7.48 & -6.99 & & & \\
\hline & $95 \%$ CI & $29.2-41.8$ & $29.4-40.2$ & $31.4-42.1$ & $31.2-41.2$ & & & \\
\hline & WGE & 35.5 & 33.5 & 36.5 & 35.5 & & & \\
\hline & (SD) & -8.21 & -6.81 & -8.9 & -6.39 & & & \\
\hline & $95 \%$ CI & $29.6-41.4$ & $28.6-38.4$ & $30.2-42.9$ & $30.9-40.0$ & & & \\
\hline \multirow{6}{*}{$\begin{array}{l}\text { Mean Power } \\
\text { (Watts/kg) }\end{array}$} & Placebo & 13.9 & 13.9 & 13.6 & 13.9 & \multirow{6}{*}{0.45} & \multirow{6}{*}{0.447} & \\
\hline & (SD) & -1.11 & -1.71 & -1.58 & -1.36 & & & \\
\hline & $95 \%$ CI & $13.1-14.7$ & $12.7-15.1$ & $12.4-14.7$ & $12.9-14.9$ & & & 0389 \\
\hline & WGE & 12.7 & 13.8 & 13.8 & 14.2 & & & \\
\hline & (SD) & -4.33 & -1.56 & -1.34 & -1.36 & & & \\
\hline & $95 \%$ CI & $9.6-15.8$ & $12.7-14.9$ & $12.9-14.8$ & $13.2-15.1$ & & & \\
\hline & Placebo & 14.1 & 14.1 & 13.7 & 14 & & & \\
\hline & (SD) & -1.15 & -1.73 & -1.62 & -1.33 & & & \\
\hline Peak Power & $95 \%$ CI & $13.3-14.9$ & $12.9-15.3$ & $12.5-14.9$ & $13.1-15.0$ & 0.583 & 0.452 & 0.786 \\
\hline & WGE & 14.1 & 14 & 14 & 14.3 & & & \\
\hline & (SD) & -1.63 & -1.56 & -1.31 & -1.35 & & & \\
\hline & $95 \%$ CI & 13.0-15.3 & $12.9-15.1$ & $13.0-14.9$ & $13.3-15.3$ & & & \\
\hline
\end{tabular}

Note. ${ }^{*} \mathrm{p}<0.05$, significantly greater compared to $2 \mathrm{~h}$ after acute eccentric exercise. WGE, wild ginseng extract; $\mathrm{G}$, group; $\mathrm{T}$, time; $\mathrm{G} \times \mathrm{T}$, group $\times$ time.

\subsection{Blood Analyses}

In this study, IL-6, cortisol, myoglobin, and total antioxidant capacity were analyzed to evaluate the changes of inflammation and muscle damage markers as well as antioxidant capacity following the acute eccentric exercise. There were no significant differences in all blood variables between the WGE and the placebo conditions. However, IL-6 $\left(F=5.671, p=0.013, \eta_{p}{ }^{2}=0.387\right)$, myoglobin $(F=23.309$, $\left.\mathrm{p}<0.001, \eta_{\mathrm{p}}{ }^{2}=0.744\right)$ and cortisol levels changed significantly across the time $(\mathrm{F}=3.553, \mathrm{p}=0.047$, $\left.\eta_{\mathrm{p}}{ }^{2}=0.282\right)$. Especially, a significant increase in IL-6 was observed only in the placebo condition $\left(\mathrm{F}=5.995, \mathrm{p}=0.014, \eta_{\mathrm{p}}{ }^{2}=0.400\right)$ while no significant difference found in the WGE condition. The results of blood analyses are presented in Figure 1. 


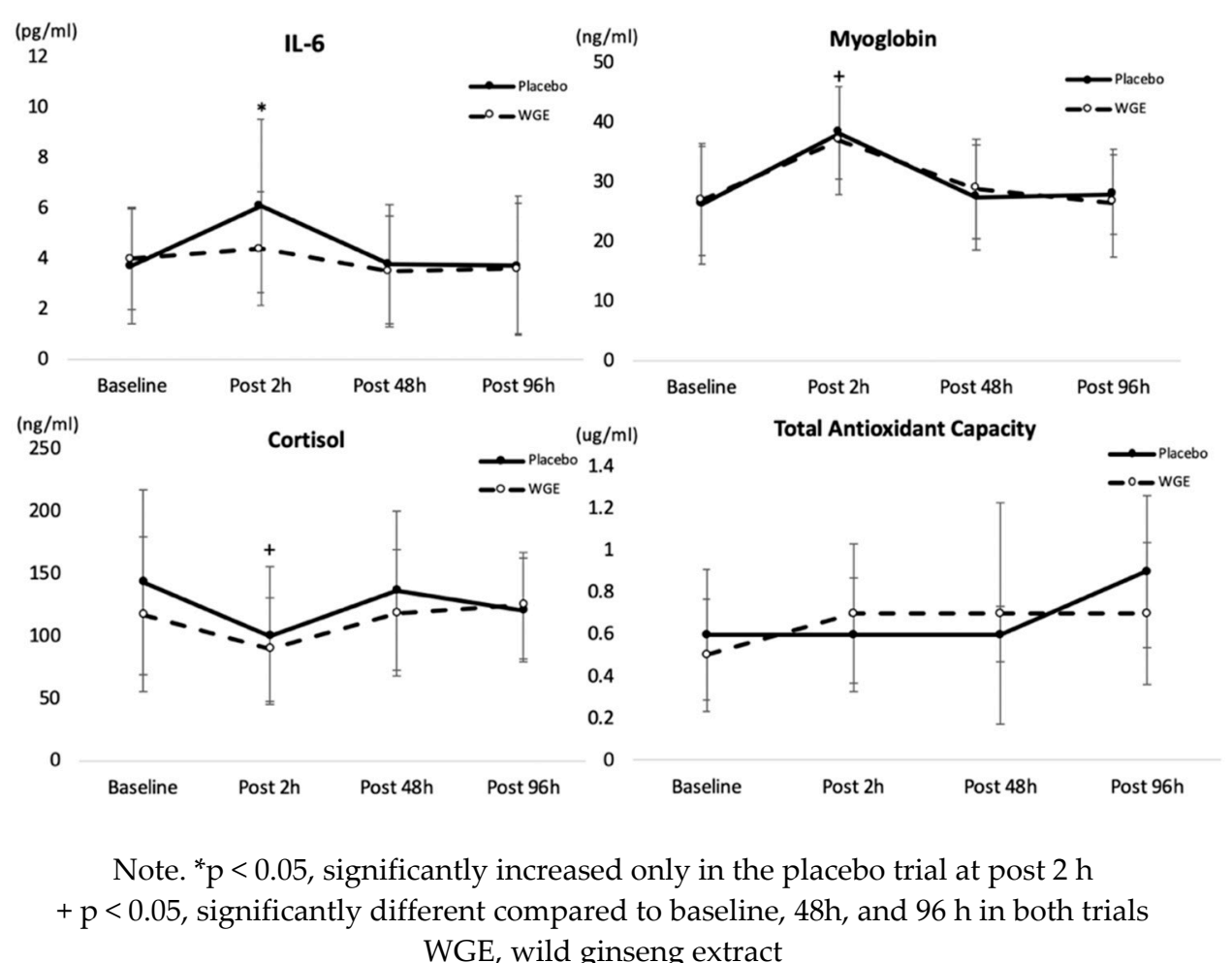

Figure 1. The results of blood markers of muscle damage.

\subsection{Perceived Muscle Soreness}

There was no significant interaction effect for group by time on perceived muscle soreness measured by VAS. However, the increased in perceived muscle soreness was observed both the WGE and the placebo conditions after $2 \mathrm{~h}$ of acute eccentric exercise $\left(\mathrm{F}=9.236, \mathrm{p}=0.001, \eta_{\mathrm{p}}{ }^{2}=0.506\right)$. The results are shown in Table 5.

Table 5. The results of perceived muscle soreness following acute eccentric exercise.

\begin{tabular}{|c|c|c|c|c|c|c|c|c|}
\hline \multirow{2}{*}{ Variables } & \multirow{2}{*}{ Group } & \multirow{2}{*}{ Base } & \multirow{2}{*}{$2 \mathrm{~h}$} & \multirow{2}{*}{$48 \mathrm{~h}$} & \multirow{2}{*}{$96 \mathrm{~h}$} & \multicolumn{3}{|c|}{ p-Value } \\
\hline & & & & & & G & $\mathbf{T}$ & $\mathrm{G} \times \mathrm{T}$ \\
\hline \multirow{4}{*}{$\begin{array}{l}\text { Perceived } \\
\text { Muscle } \\
\text { Soreness }\end{array}$} & $\begin{array}{c}\text { Placebo } \\
\text { (SD) }\end{array}$ & $\begin{array}{c}0.6 \\
(0.70)\end{array}$ & $\begin{array}{l}3.0 * \\
(2.16)\end{array}$ & $\begin{array}{c}2.3 \\
(1.89)\end{array}$ & $\begin{array}{c}0.8 \\
(1.03)\end{array}$ & \multirow{4}{*}{0.922} & \multirow{4}{*}{0.001} & \multirow{4}{*}{0.462} \\
\hline & $95 \%$ CI & $0.1-1.1$ & $1.5-4.5$ & $0.9-3.7$ & $0.1-1.5$ & & & \\
\hline & $\begin{array}{l}\text { WGE } \\
\text { (SD) }\end{array}$ & $\begin{array}{c}0.4 \\
(0.47)\end{array}$ & $\begin{array}{c}3.5 * \\
(2.34)\end{array}$ & $\begin{array}{c}1.8 \\
(1.75)\end{array}$ & $\begin{array}{c}1.2 \\
(1.69)\end{array}$ & & & \\
\hline & $95 \%$ CI & $0.0-0.7$ & $1.8-5.2$ & $0.5-3.0$ & $0.0-2.4$ & & & \\
\hline
\end{tabular}

Note. ${ }^{*} \mathrm{p}<0.05$, significantly different compared to baseline, $48 \mathrm{~h}$, and $96 \mathrm{~h}$ in both trials. WGE, wild ginseng extract; $\mathrm{G}$, group; $\mathrm{T}$, time; $\mathrm{G} \times \mathrm{T}$, group $\times$ time.

\section{Discussion}

The present study examined the efficacy of WGE on psychomotor and neuromuscular performance recovery following acute eccentric exercise in male adults. Our findings showed that the administration of WGE immediately after acute eccentric exercise and the following four days have no benefits on psychomotor and neuromuscular performance recovery. However, a favoring trend has been identified that a significant increase in IL-6 was observed only in the placebo condition, while no significant changes were found in the WGE condition. 


\subsection{Psychomotor Performance}

We examined the computer-based cognitive function test including PVT and DMS task to evaluate psychomotor performance during recovery. The supplementation of WGE following acute eccentric exercise did not provide a benefit on psychomotor performance in male adults. Consistent results have been identified in the previous study that 14 days of Korean ginseng (GINST15) supplementation prior to resistance exercise were not associated with the improvement of cognitive performance (i.e., quick board reaction time test) in healthy male and female adults [39]. A single dose of Panax ginseng (G115) for eight days also did not improve the working memory process in healthy subjects [40]. In contrast to our findings, Reay et al. reported that a single dose of Panax Ginseng (200 mg, G115) improves cognitive performance, such as serial seven task in healthy adults, but high dosages $(400 \mathrm{mg}$, G115) and placebo conditions did not improve the cognitive performance [41]. Other Ginseng studies also demonstrated that cognitive functions, such as speed of the attention task [42], and secondary memory performance of cognitive research battery [43], improved following a single dose of Panax Ginseng ( $200 \mathrm{mg}$, $400 \mathrm{mg}$, respectively). Some possible explanations, such as the modulation of blood glucose and nitric oxide (NO) production have been proposed as potential mechanisms that may contribute to the improvement of cognitive performance [41]. It was believed that one of the active ingredients, ginsenosides, contributes to the enhancement of NO synthesis [44], and it modulates the glucose metabolism and insulin secretion in patients with type II diabetes mellitus [45]. Although some possible mechanisms, as well as benefits on cognitive function, have been demonstrated in the previous studies, our study confirms that five days of ginseng supplementation following acute eccentric exercise does not provide benefits on psychomotor performance recovery in male adults. In the present study, the DMS task correction and total time were significantly reduced across the time both in WGE and placebo conditions. We assume that decreased DMS correction partially related to 'speed accuracy trade-off'. Therefore, it is difficult to confirm that a decrease in cognitive function, such as DMS correction, was due to acute eccentric exercise.

\subsection{Neuromuscular Performance}

In the present study, straight leg raise, vertical jump performance, isometric leg strength, and anaerobic power were measured as indicators of neuromuscular performance. We found that WGE supplementation has no benefit on neuromuscular performance recovery. Ginseng supplementation has long been believed to improve stamina or fatigue recovery, but it is unclear whether the apoptogenic properties can facilitate the performance recovery or not. In particular, the discrepancy among literature to confirm the roles as an ergogenic aid may be limited. While the favoring results have been found mostly in animal studies [15,16], the literature with human studies are limited. Pumpa et al. reported that five days of Panax Notoginseng supplementation, before and after downhill running exercise, did not show significant improvement in jump performance [27]. A recent study showed the 14 days of Korean Ginseng supplementation (GINST15, high dose: $960 \mathrm{mg} /$ day, low dose: $160 \mathrm{mg} /$ day) following acute resistance exercise ( 5 sets of 12 repetitions at $70 \%$ one-repetition maximum (1RMmax)) had no benefit on peak power in healthy adults [39]. However, authors pointed out an important consideration about the responder and non-responder effect in the supplementation research. Although this approach is not a novel concept, Cadwell et al. reported that the responders among high dose trials showed greater peak power compared to low dose and placebo trials [39]. Relatively long-term treatment ( $>8$ weeks) also demonstrated no benefits on neuromuscular performance, such as anaerobic peak power and mean power in active women [46]. As opposed to the current study, Liang et al. reported that 30 days of Panax notoginseng $(1350 \mathrm{mg} /$ day) supplementation have contributed to improve endurance performance time by $>7 \mathrm{~min}$ in young adults [24]. Supplementation of ginseng saponin complex mixed with taurine and other substances for 15 days improved free fatty acid utilization during exhaustive cycling tests, which resulted in improving endurance performance by average $2.94 \mathrm{~min}$ in male adults [26]. Interestingly, the efficacy of ginseng supplementation has been observed in the particular area of performance, such as endurance performance [24-26]. A recent study reported 
12-week administration of high-dose ginsenoside complex (500 mg/day) improved maximal oxygen consumption, but the efficacy was not found in muscle strength [25]. It has been proposed that ginseng supplementation improves energy utilization [15]. Although it is difficult to explain the outcomes of the animal study directly into human studies, Ma et al. reported that the administration of Panax ginseng extract improves glucose uptake, fatty acid utilization, and lower the lactate concentration that possibly contributed to the improvement of endurance swimming performance [15]. We assumed that if ginseng or active ingredients, such as ginsenosides, modulate the energy metabolism, such as glucose and free fatty acid utilization during exercise, the improvement of neuromuscular performance that predominantly utilized the energy through ATP-PCr and glycolytic energy system may be limited. In summary, we confirm that the administration of WGE immediately after an eccentric exercise, and the following four days, have no benefit on neuromuscular performance recovery, such as muscle strength and anaerobic power. Further studies may be needed to clarify whether WGE could act as a potential ergogenic aid for endurance performance.

\subsection{Inflammation Markers of Muscle Damage}

Acute intense or eccentric exercise changes markers of muscle damage and inflammation resulted in inducing delayed-onset muscle soreness [19]. Various nutritional approaches have been introduced to attenuate the inflammation process or facilitate the recovery from muscle damages [47]. In this study, blood markers, including IL-6, myoglobin, cortisol, and TAC were not significantly different between the WGE and the placebo conditions following acute eccentric exercise. However, a favoring trend has been found that the serum IL-6 level significantly increased only in the placebo condition during $2 \mathrm{~h}$ recovery, whereas this value did not significantly change in the WGE condition. Similar results have been reported in previous studies [48-50]. Jung et al. reported that 7 days of Panax ginseng supplementation $(20 \mathrm{~g} / \mathrm{d}$ ) prior to the uphill treadmill running ( $45 \mathrm{~min}$ at $10 \mathrm{~km} / \mathrm{h}$ speed with a 15 degree) attenuated the increment of IL-6 level during $2 \mathrm{~h}$ and $3 \mathrm{~h}$ recovery period in young adults [48]. Another study also demonstrated that administrations of ginseng-based steroid $\operatorname{Rg} 1(5 \mathrm{mg})$ one night and one hour before 60-min cycling exercise suppressed the exercise-induced expression of IL-10 mRNA in quadriceps muscle [49]. Recently, Pumpa et al. reported that the level of serum IL-6 declined after downhill running in the ginseng group whereas the placebo group increased up to $4 \mathrm{~h}$ [27]. However, their findings revered $24 \mathrm{~h}$ after downhill running where the placebo group demonstrated a rapid return to baseline compared to the ginseng group. Interestingly, the placebo condition in this study also returned the IL-6 level to near baseline $24 \mathrm{~h}$ after eccentric exercise. A question arises based on the present and the previous studies whether the benefits of acute ginseng administration only valid during the first $2-4 \mathrm{~h}$ after eccentric exercise. However, this question should be approached carefully in the future study because the present and the previous data demonstrated inconsistent patterns from $24 \mathrm{~h}$ to $96 \mathrm{~h}$ after acute eccentric exercise. Although our study revealed a favoring trend at the first $2 \mathrm{~h}$ after the exercise, the benefit is not guaranteed until future research with a large sample size is conducted to clarify the anti-inflammation process in response to acute eccentric exercise.

Myoglobin is a muscle protein that is released from the damaged muscle following high intense eccentric exercise [19]. In the present study, the myoglobin level increased two hours after acute eccentric exercise, but no difference was found between the conditions. Lin et al. reported 12 weeks of Panax ginseng supplementation did not change inflammation adaptation, including muscle damage, oxidative, and inflammatory biomarkers to eccentric exercise training [51]. Pumpa et al. applied 5 bouts of 8 min downhill running at $80 \%$ of maximal heart rate (HRmax) with lowered $-10^{\circ}$ and participants received Panax notoginseng capsule (4000 mg/day) or placebo for 5 times (at $1 \mathrm{~h}$ prior to exercise and the following four days) in a crossover design. The author reported that myoglobin significantly increased after downhill running, but no significant differences were observed between conditions that support our result [27]. Cortisol is a glucocorticoid hormone that regulates energy metabolism during exercise [52]. It also interacts with inflammatory markers and nutritional supplementation, 
such as carbohydrates, and has been shown to lower cortisol levels after intense exercise [53]. In the present study, there were no difference in serum cortisol level between the WGE and placebo conditions. Youl et al. reported that a single bout of ginseng root extract $(20 \mathrm{~g})$ administered following a standardized exercise did not make a significant difference in cortisol levels [54]. Thus, it is confirmed that cortisol response following eccentric exercise was not influenced by ginseng supplement.

There are some strengths and limitations in the present study that need to be considered when interpreting the data. This study was well designed with randomized, double-blinded, placebo controlled, and crossover design. It assessed a wide range of markers of muscle damage and neuromuscular performance variables assessing effect of WGE in response to the eccentric exercise. However, small sample size may impact the statistical significance of the findings. Secondly, the outcomes can result differently by exercise protocols. The exercise protocol in this study was modified from the previous literature that was performed with healthy adults [30,31]. Although the current eccentric exercise protocol demonstrated a change of markers of muscle damage, such as myoglobin, IL-6, and cortisol, no significant changes in neuromuscular performance were observed after acute eccentric exercise. These results may tell us that the exercise protocol used in the present study may be insufficient to induce the delayed onset of muscle soreness.

\section{Conclusions}

Our findings indicate that the administration of WGE $(700 \mathrm{mg} /$ day $)$ immediately after eccentric exercise and the following four days have no benefits on psychomotor and neuromuscular performance recovery in male adults. However, the acute WGE supplementation may attenuate the eccentric exercise-induced inflammatory process, such as IL-6, but a future study with a large sample size is required to clarify the anti-inflammation process in response to acute eccentric exercise.

Author Contributions: Conceptualization, H.C.J. and S.L.; Formal analysis, H.C.J. and S.L.; investigation, H.C.J., N.H.L., Y.C.K., and S.L.; methodology, H.C.J., N.H.L., Y.C.K., and S.L.; Project administration, S.L.; Supervision, S.L. writing-original draft preparation, H.C.J.; writing-review and editing, H.C.J., S.L. All authors have read and agreed to the published version of the manuscript.

Funding: This research received no external funding.

Acknowledgments: All authors wish to thank the participants who participated in this study.

Conflicts of Interest: The authors declare no conflict of interest.

\section{References}

1. Provino, R. The role of adaptogens in stress management. Aus. J. Med. Herbal. 2010, 22, 41.

2. Bach, H.V.; Kim, J.; Myung, S.K.; Cho, Y. Efficacy of Ginseng supplements on fatigue and physical performance: A meta-analysis. J. Kor. Med. Sci. 2016, 31, 1879-1886. [CrossRef] [PubMed]

3. Liu, D.; Li, Y.G.; Xu, H.; Sun, S.Q.; Wang, Z.T. Differentiation of the root of cultivated ginseng, mountain cultivated ginseng and mountain wild ginseng using FT-IR and two-dimensional correlation IR spectroscopy. J. Mol. Struc. 2008, 883, 228-235. [CrossRef]

4. Murthy, H.N.; Dandin, V.S.; Park, S.Y.; Paek, K.Y. Quality, safety and efficacy profiling of ginseng adventitious roots produced in vitro. Appl. Microbiol. Biotechnol. 2018, 102, 7309-7317. [CrossRef]

5. Park, J.S.; Park, E.M.; Kim, D.H.; Jung, K.; Jung, J.S.; Lee, E.J.; Hyun, J.W.; Kang, H.S.; Kim, H.S. Anti-inflammatory mechanism of ginseng saponins in activated microglia. J. Neuroimmunol. 2009, 209, 40-49. [CrossRef]

6. Lee, C.H.; Kim, J.H. A review on the medicinal potentials of ginseng and ginsenosides on cardiovascular diseases. J. Ginseng. Res. 2014, 38, 161-166. [CrossRef]

7. Sohn, E.H.; Yang, Y.J.; Koo, H.J.; Park, D.W.; Kim, Y.J.; Jang, K.H.; Namkoong, K.H.; Kang, S.C. Effects of Korean ginseng and wild simulated cultivation ginseng for muscle strength and endurance. Kor. J. Plant. Res. 2012, 25, 657-663. [CrossRef] 
8. Chang, W.H.; Tsai, Y.L.; Huang, C.Y.; Hsieh, C.C.; Chaunchaiyakul, R.; Fang, Y.; Lee, S.D.; Kuo, C.H. Null effect of ginsenoside $\mathrm{Rb} 1$ on improving glycemic status in men during a resistance training recovery. J. Int. Soc. Sports Nutr. 2015, 12, 34. [CrossRef]

9. Cheng, Y.; Shen, L.H.; Zhang, J.T. Anti-amnestic and anti-aging effects of ginsenoside Rg1 and Rb1 and its mechanism of action. Acta. Pharm. Sin. 2005, 26, 143-149. [CrossRef]

10. Nah, S.Y.; Kim, D.H.; Rhim, H. Ginsenosides: Are any of them candidates for drugs acting on the central nervous system? CNS Drug Rev. 2007, 13, 381-404. [CrossRef] [PubMed]

11. Lee, B.; Kim, H.; Shim, I.; Lee, H.; Hahm, D.H. Wild ginseng attenuates anxiety-and depression-like behaviors during morphine withdrawal. J. Microbiol. Biotechnol. 2011, 21, 1088-1096. [CrossRef] [PubMed]

12. Lee, S.T.; Chu, K.; Sim, J.Y.; Heo, J.H.; Kim, M. Panax ginseng enhances cognitive performance in Alzheimer disease. Alzheimer Dis. Assoc. Disord. 2008, 22, 222-226. [CrossRef] [PubMed]

13. Kim, J.; Kang, D.I. A descriptive statistical approach to the Korean pharmacopuncture therapy. J. Acupunct. Meridian Stud. 2010, 3, 141-149. [CrossRef]

14. Bahrke, M.S.; Morgan, W.P. Evaluation of the ergogenic properties of ginseng. Sports Med. 2000, 29, 113-133. [CrossRef]

15. Ma, G.D.; Chiu, C.H.; Hsu, Y.J.; Hou, C.W.; Chen, Y.M.; Huang, C.C. Changbai Mountain ginseng (Panax ginseng CA Mey) extract supplementation improves exercise performance and energy utilization and decreases fatigue-associated parameters in mice. Molecules 2017, 22, 237. [CrossRef]

16. Oliynyk, S.; Oh, S. Actoprotective effect of ginseng: Improving mental and physical performance. J. Ginseng Res. 2013, 37, 144. [CrossRef]

17. Gleeson, M. Immune function in sport and exercise. J. Appl. Physiol. 2007, 103, 693-699. [CrossRef]

18. Matthews, C.E.; Ockene, I.S.; Freedson, P.S.; Rosal, M.C.; Merriam, P.A.; Hebert, J.R. Moderate to vigorous physical activity and risk of upper-respiratory tract infection. Med. Sci. Sports Exerc. 2002, 34, 1242-1248. [CrossRef]

19. Sayers, S.P.; Clarkson, P.M. Short-term immobilization after eccentric exercise. Part II: Creatine kinase and myoglobin. Med. Sci. Sports Exerc. 2003, 35, 762-768. [CrossRef]

20. Banerjee, A.K.; Mandal, A.; Chanda, D.; Chakraborti, S. Oxidant, antioxidant and physical exercise. Mol. Cell Biochem. 2003, 253, 307-312. [CrossRef]

21. Cheung, K.; Hume, P.A.; Maxwell, L. Delayed onset muscle soreness. Sports Med. 2003, 33, $145-164$. [CrossRef] [PubMed]

22. Nottle, C.; Nosaka, K. Changes in power assessed by the Wingate Anaerobic Test following downhill running. J. Strength Cond. Res. 2007, 21, 145-150. [CrossRef] [PubMed]

23. Skurvydas, A.; Brazaitis, M.; Kamandulis, S.; Sipaviciene, S. Muscle damaging exercise affects isometric force fluctuation as well as intraindividual variability of cognitive function. J. Motor Behav. 2010, 42, 179-186. [CrossRef] [PubMed]

24. Liang, M.T.; Podolka, T.D.; Chuang, W.J. Panax notoginseng supplementation enhances physical performance during endurance exercise. J. Strength Cond. Res. 2005, 19, 108. [CrossRef] [PubMed]

25. Lee, E.S.; Yang, Y.J.; Lee, J.H.; Yoon, Y.S. Effect of high-dose ginsenoside complex (UG0712) supplementation on physical performance of healthy adults during a 12-week supervised exercise program: A randomized placebo-controlled clinical trial. J. Ginseng Res. 2018, 42, 192-198. [CrossRef] [PubMed]

26. Yeh, T.S.; Chan, K.H.; Hsu, M.C.; Liu, J.F. Supplementation with soybean peptides, taurine, Pueraria isoflavone, and ginseng saponin complex improves endurance exercise capacity in humans. J. Med. Food 2011, 14, 219-225. [CrossRef]

27. Pumpa, K.L.; Fallon, K.E.; Bensoussan, A.; Papalia, S. The effects of Panax notoginseng on delayed onset muscle soreness and muscle damage in well-trained males: A double blind randomised controlled trial. Complement. Ther. Med. 2013, 21, 131-140. [CrossRef]

28. Jackson, A.S.; Pollock, M.L. Generalized equations for predicting body density of men. Br. J. Nutr. 2004, 91, 161-168. [CrossRef]

29. Siri, W.E. Body composition from fluid spaces and density: Analysis of methods. 1961. Nutrition 1993, 9 , 480-491.

30. Peake, J.M.; Suzuki, K.; Wilson, G.; Hordern, M.; Nosaka, K.; Mackinnon, L.; Coombes, J.S. Exercise-induced muscle damage, plasma cytokines, and markers of neutrophil activation. Med. Sci. Sports Exerc. 2005, 37, 737-745. [CrossRef] 
31. Kirby, T.J.; Triplett, N.T.; Haines, T.L.; Skinner, J.W.; Fairbrother, K.R.; McBride, J.M. Effect of leucine supplementation on indices of muscle damage following drop jumps and resistance exercise. Amino Acids 2012, 42, 1987-1996. [CrossRef] [PubMed]

32. Hwang, J.; Castelli, D.M.; Gonzalez-Lima, F. The positive cognitive impact of aerobic fitness is associated with peripheral inflammatory and brain-derived neurotrophic biomarkers in young adults. Physiol. Behav. 2017, 179, 75-89. [CrossRef] [PubMed]

33. Jung, H.C.; Lee, N.H.; Lee, S. Jumping exercise restores stretching-induced power loss in healthy adults. Mont. J. Sports Sc. Med. 2018, 7, 55-62. [CrossRef]

34. Abizanda, P.; Navarro, J.L.; García-Tomás, M.I.; López-Jiménez, E.; Martínez-Sánchez, E.; Paterna, G. Validity and usefulness of hand-held dynamometry for measuring muscle strength in community-dwelling older persons. Arch. Gerontol. Geriatr. 2012, 54, 21-27. [CrossRef]

35. Arnold, C.M.; Warkentin, K.D.; Chilibeck, P.D.; Magnus, C.R. The reliability and validity of handheld dynamometry for the measurement of lower-extremity muscle strength in older adults. J. Strength Cond. Res. 2010, 24, 815-824. [CrossRef]

36. Martin, J.C.; Diedrich, D.; Coyle, E.F. Learning effects associated with maximal power testing: Implications for validity. Int. J. Sports Med. 2000, 21, 485-487. [CrossRef]

37. Lee, N.H.; Jung, H.C.; Ok, G.; Lee, S. Acute effects of Kinesio taping on muscle function and self-perceived fatigue level in healthy adults. Eur. J. Sport Sci. 2017, 17, 757-764. [CrossRef]

38. Lakens, D. Calculating and reporting effect sizes to facilitate cumulative science: A practical primer for t-tests and ANOVAs. Front. Psychol. 2013, 4, 863. [CrossRef]

39. Caldwell, L.K.; DuPont, W.H.; Beeler, M.K.; Post, E.M.; Barnhart, E.C.; Hardesty, V.H.; Anders, J.P.; Borden, E.C.; Volek, J.S.; Kraemer, W.J. The effects of a Korean ginseng, GINST15, on perceptual effort, psychomotor performance, and physical performance in men and women. J. Sports Sci. Med. 2018, 17, 92.

40. Reay, J.L.; Scholey, A.B.; Kennedy, D.O. Panax ginseng (G115) improves aspects of working memory performance and subjective ratings of calmness in healthy young adults. Hum. Psychopharmacol. 2010, 25, 462-471. [CrossRef]

41. Reay, J.L.; Kennedy, D.O.; Scholey, A.B. Single doses of Panax ginseng (G115) reduce blood glucose levels and improve cognitive performance during sustained mental activity. J. Psychopharmacol. 2005, 19, 357-365. [CrossRef] [PubMed]

42. Kennedy, D.O.; Haskell, C.F.; Wesnes, K.A.; Scholey, A.B. Improved cognitive performance in human volunteers following administration of guarana (Paullinia cupana) extract: Comparison and interaction with Panax ginseng. Pharmacol. Biochem. Behav. 2004, 79, 401-411. [CrossRef] [PubMed]

43. Kennedy, D.O.; Scholey, A.B.; Wesnes, K.A. Modulation of cognition and mood following administration of single doses of Ginkgo biloba, ginseng, and a ginkgo/ginseng combination to healthy young adults. Physio. Behav. 2002, 75, 739-751. [CrossRef]

44. Chen, X.; Lee, T.J.F. Ginsenosides-induced nitric oxide-mediated relaxation of the rabbit corpus cavernosum. Br. J. Pharmacol. 1995, 115, 15-18. [CrossRef]

45. Vuksan, V.; Sievenpiper, J.L.; Koo, V.Y.; Francis, T.; Beljan-Zdravkovic, U.; Xu, Z.; Vidgen, E. American ginseng (Panax quinquefolius $\mathrm{L}$ ) reduces postprandial glycemia in nondiabetic subjects and subjects with type 2 diabetes mellitus. Arch. Intern. Med. 2000, 160, 1009-1013. [CrossRef]

46. Engels, H.J.; Kolokouri, I.; Cieslak, T.J., II; Wirth, J.C. Effects of ginseng supplementation on supramaximal exercise performance and short-term recovery. J. Strength Cond. Res. 2001, 15, 290-295.

47. Hennigar, S.R.; McClung, J.P.; Pasiakos, S.M. Nutritional interventions and the IL-6 response to exercise. FASEB J. 2017, 31, 3719-3728. [CrossRef]

48. Jung, H.L.; Kwak, H.E.; Kim, S.S.; Kim, Y.C.; Lee, C.D.; Byurn, H.K.; Kang, H.Y. Effects of Panax ginseng supplementation on muscle damage and inflammation after uphill treadmill running in humans. Am. J. Chin. Med. 2011, 39, 441-450. [CrossRef]

49. Hou, C.W.; Lee, S.D.; Kao, C.L.; Cheng, I.S.; Lin, Y.N.; Chuang, S.J.; Chen, C.Y.; Ivy, J.L.; Haung, C.Y.; Kuo, C.H. Improved inflammatory balance of human skeletal muscle during exercise after supplementations of the ginseng-based steroid Rg1. PLOS ONE 2015, 10. [CrossRef]

50. Flanagan, S.D.; DuPont, W.H.; Caldwell, L.K.; Hardesty, V.H.; Barnhart, E.C.; Beeler, M.K.; Post, E.M.; Vlek, J.S.; Kraemer, W.J. The effects of a Korean ginseng, GINST15, on hypo-pituitary-adrenal and oxidative activity induced by intense work stress. J. Med. Food 2018, 21, 104-112. [CrossRef] 
51. Lin, H.F.; Chou, C.C.; Chao, H.H.; Tanaka, H. Panax ginseng and Salvia miltiorrhiza supplementation during eccentric resistance training in middle-aged and older adults: A double-blind randomized control trial. Complement. Ther. Med. 2016, 29, 158-163. [CrossRef] [PubMed]

52. Papanicolaou, D.A.; Petrides, J.S.; Tsigos, C.; Bina, S.; Kalogeras, K.T.; Wilder, R.; Gold, P.W.; Deuster, G.P.; Chrousos, G.P. Exercise stimulates interleukin-6 secretion: Inhibition by glucocorticoids and correlation with catecholamines. Am. J. Physiol. 1996, 271, E601-E605. [CrossRef] [PubMed]

53. Nehlsen-Cannarella, S.L.; Fagoaga, O.R.; Nieman, D.C.; Henson, D.A.; Butterworth, D.E.; Schmitt, R.L.; Bailey, E.M.; Warren, B.J.; Utter, A.; Davis, J.M. Carbohydrate and the cytokine response to $2.5 \mathrm{~h}$ of running. J. Appl. Physiol. 1997, 82, 1662-1667. [CrossRef] [PubMed]

54. Youl, H.K.; Hwan, S.K.; Jun, W.L.; Byrne, H.K. Effects of ginseng ingestion on growth hormone, testosterone, cortisol, and insulin-like growth factor 1 responses to acute resistance exercise. J. Strength Cond. Res. 2002, 16, 179-183. [CrossRef]

(C) 2020 by the authors. Licensee MDPI, Basel, Switzerland. This article is an open access article distributed under the terms and conditions of the Creative Commons Attribution (CC BY) license (http://creativecommons.org/licenses/by/4.0/). 